\title{
A contribution of Natural Language Processing to the study of semantic memory loss in patients with Alz- heimer's disease
}

\author{
Beatriz Pérez Cabello de Alba ${ }^{1}$ \\ National University for Distance Learning, Madrid
}

\begin{abstract}
This paper addresses semantic memory loss from the perspective of Natural Language Processing. Dementia disorders and, in particular, Alzheimer's disease (AD) present a loss of cognitive functions, being one of them semantic memory impairment. We set from a study conducted by Grasso, Díaz \& Peraita (2011) where they analysed the production of features of four semantic categories (2 Living Beings and 2 Non Living Beings) of healthy subjects and patients with different levels of Alzheimer's disease, taken from the Linguistic corpus of semantic categories definitions elaborated by Peraita \& Grasso (2010). The aim of this work is to enhance the protocol of semantic features employed in that study by using Natural Language Processing systems such as FunGramKB (Periñán-Pascual \& Arcas Túnez 2004, 2005, 2006, 2007, 2010). This lexical-conceptual knowledge base incorporates a series of feature descriptors for the definition of semantic knowledge which, together with the inheritance and inference relations established among concepts in the ontology, will enrich the collection of semantic features used in the test of semantic attributes production for the detection of semantic memory impairment (Grasso, Díaz \& Peraita, 2011).
\end{abstract}

Keywords: Natural Language Processing, FunGramKB, Semantic memory loss, Alzheimer's disease.

\section{Introduction}

Many studies on semantic memory loss in patients with Alzheimer's disease (AD) have shown a lower production of semantic features compared to healthy controls

Corresponding author - Dpto. de Filologías Extranjeras y sus Lingüísticas Facultad de Filología. UNED, c/ Senda del Rey, 7 - 28040 Madrid.

Email: bperez-cabello@flog.uned.es 
along with a differential semantic loss in Living Beings (LB) and Non Living Beings $(\mathrm{NLB})^{2}$. In this work we set from the study carried out by Grasso, Díaz \& Peraita (2011) that analyses the production of features of four semantic categories (2 LB and 2 NLB). The purpose of the study was to analyse the production of semantic attributes obtained from the Corpus of definitions of semantic categories (Peraita \& Grasso, 2010) and to examine if there were differences in semantic memory loss between living beings and non-living being categories. In the light of the results, we believe that by using Natural Language Processing (NLP) tools such as FunGramKB, we could enrich the protocol of features of the categories used in the referred study. As we will explain later on, FunGramKB is a conceptual system based on a symbolic approach. It consists of a lexical module for the storage of linguistic knowledge, and a conceptual module, which contains non-linguistic knowledge. In this work we will use the knowledge base's ontology in order to define conceptual categories.

We could even go one step further by predicting which features of a given category are damaged in a lexical-conceptual string with the help of FunGramKB ontology. In this way, we claim that we can contribute to a more detailed diagnosis of semantic memory loss.

This paper is structured as follows: in Section 2 we give a brief introduction to the concepts of memory and semantic memory; in Section 3 we present a study on semantic memory impairment in Alzheimer's disease, based on a Corpus of semantic categories definitions elaborated by Peraita \& Grasso (2010); in Section 4 we make a proposal for using FunGramKB ontology with a view to enrich studies on semantic memory impairment; in Section 5 we will explain the role of the inheritance and inference relations which pervade the ontology as well as the list of semantic features or descriptors which appear in the conceptual definition of the entities in FunGramKB's ontology. Finally, in Section 6 we bring the conclusions about this work.

\section{Definition of memory and semantic memory}

Within the field of Cognitive psychology, Atkinson \& Shriffrin (1968) proposed the multi store model of memory, which accounts for 3 stores: sensory memory, shortterm memory (STM) and long-term memory (LTM). Although this model has been

According to Rodríguez-Rojo et al. (2015, p. 1) "the presence of categorical impairment in $A D$ remains unclear and several studies are inconsistent regarding whether these deficits are present or not in these patients". 
criticized for being too simplistic, it serves the purpose of this work to show the storage where semantic memory belongs.

In the model, as it is illustrated in Figure 1, information goes from one store to the next in a linear way and, in McLeod's words (2007), "this process has been described as an information processing model (like a computer) with an input, process and output".

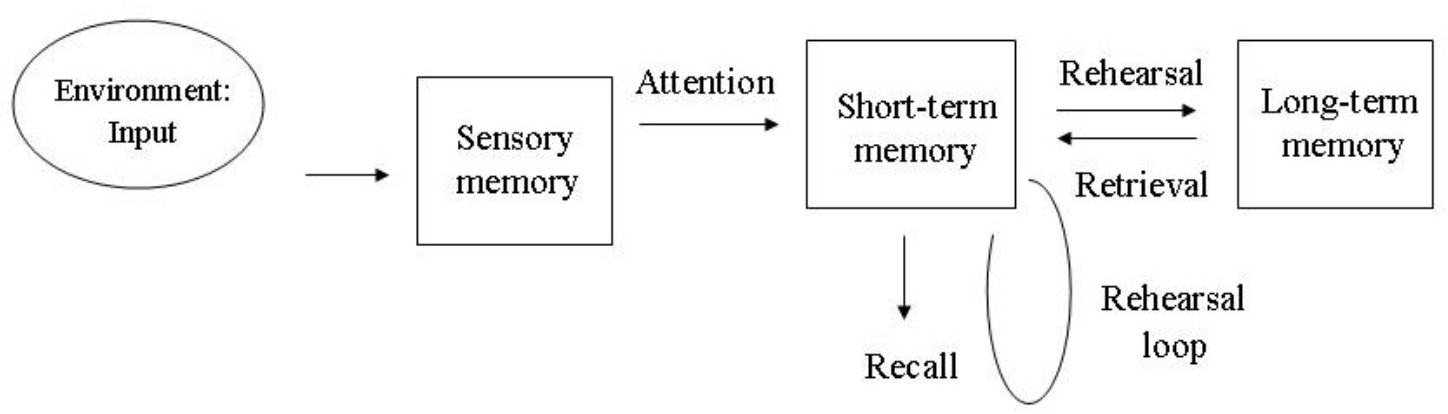

Figure 1. The Multi Store Model of Memory. http://www.simplypsychology.org/multi-store.html.

Following this linear model, firstly information (input) is detected by the sense organs and enters the sensory memory. As long as attention is paid to that information, it enters the short-term memory. Information from the STM is transferred to the LTM only if that information is rehearsed by repeating the stimulus. Atkinson \& Shiffrin (1968) initially described this type of rehearsal as maintenance rehearsal. Later on, Raaijmakers \& Shiffrin (2003) suggested that rehearsal could be elaborative (i.e. the stimulus is organized into something meaningful so that it is processed deeply and remembered better).

As explained in McLeod (2007) each store has its characteristics in terms of encoding, capacity and duration, which are described below:

Type 1. Sensory Memory is the shortest-term element of memory. It is the ability to retain impressions of sensory information after the original stimuli have ended. Its duration goes from $1 / 4$ to $1 / 2$ second, it has got a very large capacity, and it stores all sorts of sensory experience. All of our senses have sensory memory systems but the systems focused on by the Atkinson-Shiffrin model relate to sight and sound, known as iconic and echoic memory respectively.

Type 2. Short Term Memory has a capacity of storing seven plus or minus two items (Miller, 1956), its duration, according to Aktkinson \& Shiffrin (1971), seems to be between 15 and 30 seconds, and it is primarily auditory.

Type 3. Long Term Memory could have an unlimited capacity, the main constraint 
on recall being accessibility rather than availability. Its duration might be a few minutes or a lifetime. Its suggested encoding modes are mainly semantic (meaning) and visual (pictorial) but can be acoustic too.

Since this work is concerned with semantic memory, which is found in LTM, we are going to focus on that type of memory and the two different types that we can find within: episodic memory and semantic memory (Tulving, 1972). While episodic memory is autobiographic, i.e. memory which keeps the events of our past in the temporal spatial context where they occurred, semantic memory is related to general knowledge of the world and concepts.

As we will see in Section 4, the knowledge base we are going to present in this paper has got a conceptual module which stores three types of information: procedural knowledge stored through script-like schemata (cognicon), instances of entities and events stored through snapshots and stories (onomasticon), and 'a catalogue of all the concepts that a person has in mind when talking about everyday situations' (Mairal Usón \& Periñán-Pascual, 2009, pp. 219-220), stored through meaning postulates (ontology). The different types of LTM distinguished by Tulving, i.e. episodic memory and semantic memory, correlate in FunGramkB with the Onomasticon and the Cognicon modules, and the Ontology module, respectively.

\section{Semantic memory impairment in Alzheimer's disease. A study based on an oral corpus of verbal definitions}

Alzheimer's disease (AD) is characterized by semantic memory loss from the early stages of the disease. Studies on semantic memory and knowledge representation in patients with Alzheimer's disease have shown a lower production of semantic features compared to healthy controls, along with a differential semantic loss in Living Beings (LB) and Non Living Beings (NLB).

Since the decline in semantic memory observed in Alzheimer's disease is presumed to result from progressive loss of the attributes underlying category representation (Peraita, Díaz \& Anllo-Vento, 2008), we agree that a corpus of oral definitions is a methodological tool which can help with the characterization of AD according to the semantic deterioration found. In this section we are going to succinctly present the study carried out by Grasso, Díaz \& Peraita (2011) about Semantic Memory impairment in Alzheimer's disease, based on the Linguistic corpus of semantic categories definitions compiled by Peraita \& Grasso (2010). The purpose of this review is to detect whether a NLP tool can help make this kind of studies more finegrained so that they can better point to the diagnosis of Alzheimer's disease.

The objectives of the study were to analyse the production of semantic attributes 
obtained from a corpus of oral definitions of semantic categories and to examine if there were differences between living beings and non-living being categories. The participants of the study were 211 adults from Spain and Argentina, aged from 60 to 90 , divided in 2 groups, one of cognitive healthy subjects $(n=107)$ and the other one of patients with $A D(n=104)$. The method used was a category definition test which is part of the (EMSDA)i ${ }^{3}$ battery for the evaluation of semantic memory in patients with Alzheimer type dementia. This is a verbal test, which consists in a free oral production test with a 2-minute time restriction. With this test one can evaluate the semantic knowledge possessed by the subject about a series of categories. This corpus is therefore the result of a "recollection" task where subjects were asked to say all they knew about a prompted word. Their answers were recorded and later transcribed. This task reports what data is more accessible when the subject is asked to verbalize this information.

The semantic analysis of each definition was carried out by segmenting the semantic features produced following Peraita, Elosúa \& Linares' model represented in Figure 2. 


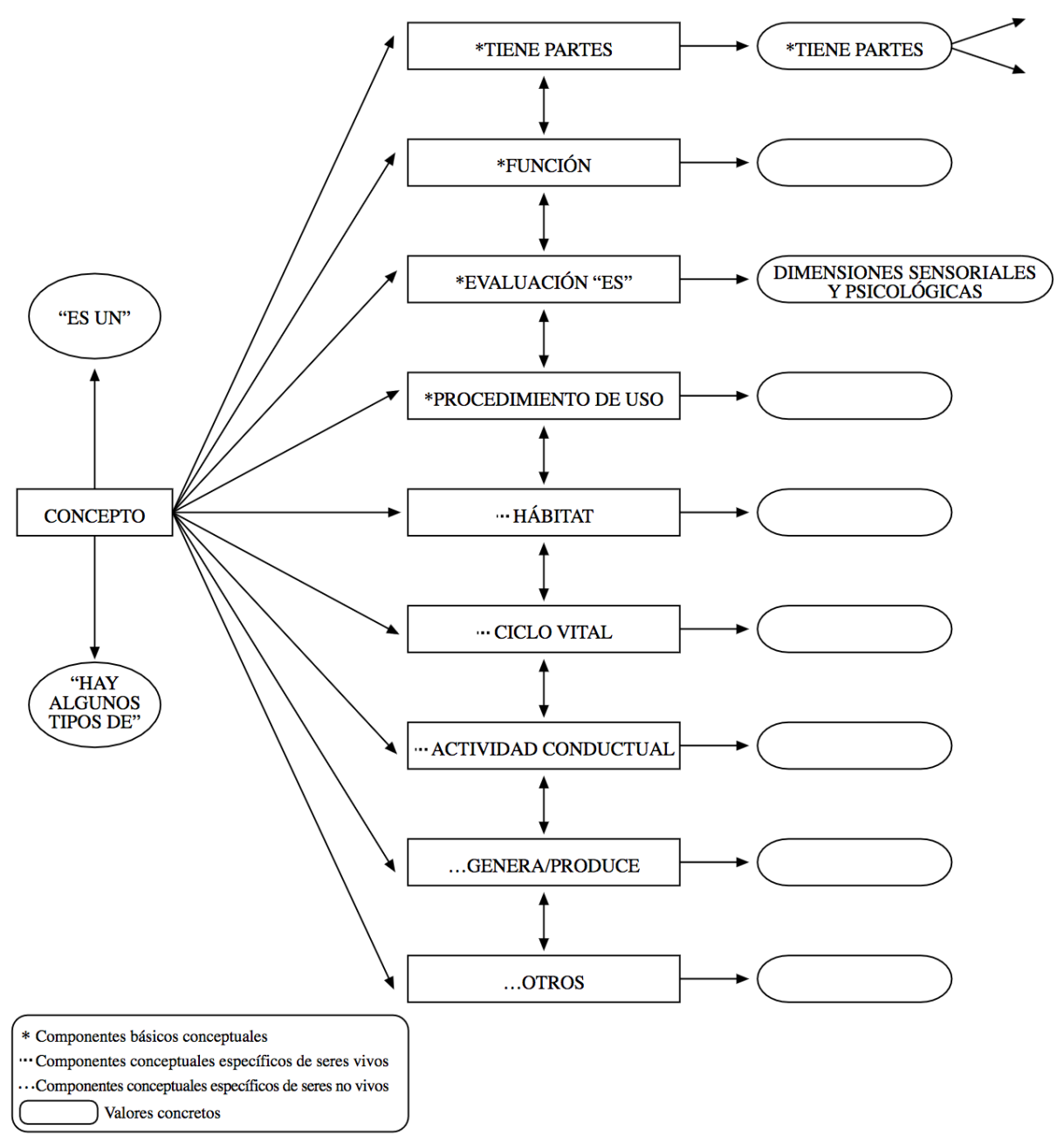

Figure 2. Model of semantic features for the conceptual representation of elements within $L B$ and NLB semantic categories. Peraita, Elosúa \& Linares (1992).

In the above-mentioned model, the common conceptual components for the categories LB and NLB are, in the vertical axis, Taxonomy, i.e. «is a ...», for example "An apple is a fruit", and Typification, i.e. «there are different types of ...», for example "There are many types of dogs". In the horizontal axis we find Composition (wholepart), for example "A car has got steering wheel, brake, clutch, accelerator, etc."; Function, i.e. «is used for...», for example "A dog helps to guide blind people"; Evaluation, referred to physical-perceptual dimensions, i.e. "colour, shape, size, texture, ...etc.» and to social and affective dimensions, i.e. «kindness, pleasure...», for example "An apple is red", "An apple is tasty"; Procedure of use, i.e. «is used in a certain way...», for example "You drive a car with the steering wheel".

Within the horizontal axis there are specific conceptual components for Living 
Beings such as Place or habitat, i.e. « it lives in ...» «it can be found in ...», for example "A lion lives in the jungle"; Life cycle, i.e. «it is born, it reproduces ...» and Behavioural activity, i.e. «it swims, runs ...».

On the other hand, we also find conceptual components for Non Living Beings such as Production, i.e. «it produces ...» or a Characteristic activity, i.e. "A hammer hammers".

In the study reviewed here (Grasso, Díaz \& Peraita, 2011) the authors' aim was to determine whether the impairments in semantic processing observed in Alzheimer's disease depended on the type of semantic relation that defines various living and non-living semantic categories. For that purpose they only took into account the following three features or semantic attributes: (1) perceptual: its distinct perceptual features (e.g., colour or form), for example "An apple is red". "An apple is tasty"; (2) functional: the object's function or its predominant use, as in "A dog helps to guide blind people", and (3) taxonomic: the ascription of an object to a specific conceptual and ontological category, for instance "An apple is a fruit".

The authors obtained 848 verbal definitions from four semantic categories: two of Living Beings 'manzana' (apple) and 'perro' (dog), and two of Non Living Beings 'coche' (car) and 'pantalón' (trousers). The results of the study showed that healthy participants produce more attributes than patients with $A D$ in all categories. Also, in both groups there is a bigger proportion of evaluative attributes, which are referred to perceptual properties (such as form, colour, etc.) as well as social and affective properties (kindness, goodness, sympathy, etc.). The analysis by domains (animate vs. inanimate) shows that in both groups there is a major proportion of attributes belonging to animate categories.

To close this section, we would like to point out that although several studies like the one reviewed here have found that category/domain effects (i.e., a relative impairment of one semantic category/domain respect to the other) are present in patients with Alzheimer's disease, others have described impairment of both domains, and several works have found no category effects in $A D$ patients (Rodríguez-Rojo, Lugo-Marín, \& Moreno-Martínez, 2015).

\section{A proposal for using FunGramKB ontology in the study of semantic memory}

We propose to use FunGramKB to enrich the model used by Grasso, Díaz \& Peraita (2011) exposed in Section 3. By using FunGramKB we can access data from the conceptual entries in the core ontology, which means that we will be able to retrieve more semantic features of categories within a patient's production in order to (1) 
check which features within a category are damaged, and (2) establish enriched conceptual networks which would reflect (a) inheritance relations, i.e. the onomasiological structure of concepts, and (b) inference relations, i.e. the concepts a given conceptual unit is linked to through its meaning postulates.

Since semantic memory is stored in the ontological module, concepts in FunGramKB ontology would account for Peraita \& Grasso's categories, and the predications that define each concept in FunGramKB would substantially enrich the characteristics or features of the categories used in their study.

At this point, a brief introduction to FunGramKB's lexico-conceptual architecture is needed to understand the correspondences between the terms used in the study conducted by Grasso, Díaz \& Peraita (2011) and the ones belonging to our NLP system.

FunGramKB is a multilingual and multipurpose system for Natural Language Processing which consists of a lexical level for the storage of linguistic knowledge, and a conceptual level, which contains non-linguistic knowledge in its three subcomponents: (i) the Ontology, which presents in a hierarchical way 'a catalogue of all the concepts that a person has in mind when talking about everyday situations' (Mairal Usón \& Periñán-Pascual, 2009 pp. 219-220), and in which semantic knowledge is stored in the form of meaning postulates; (ii) the Cognicon, where procedural knowledge is stored through script-like schemata (cognitive macrostructures); and (iii) the Onomasticon, where instances of entities and events are stored through snapshots and stories.

Since semantic memory is stored in the ontological module, we will just focus on the ontological module of FunGramKB. ${ }^{4}$

In FunGramKB's core ontology we find three types of concepts, which go from the more general to the more concrete. As defined in Periñán-Pascual \& Arcas Túnez (2004), metaconcepts constitute the upper level in the taxonomy preceded by symbol \#. They are not linked to any lexical unit. There are three root metaconcepts: \#ENTITY, \#ATTRIBUTE and \#EVENT. Basic concepts, in their turn, are used as defining units enabling the construction of meaning postulates for basic concepts and terminal concepts, and they are also used as selection preferences in conceptual and lexical frames. They are preceded by symbol +. The terminal level is not hierarchically structured although terminal concepts are not presented indiscriminately as members of concept lists associated to basic concepts, but terminals are supplied with a series of properties. They are preceded by symbol $\$$,

For a complete description of FunGramKB, we address the interested reader to the work by Periñán-Pascual \& Arcas Túnez (2011) and Mairal Usón (2012). 
and they cannot take part in meaning postulates.

As a way of example we will examine the basic concept +APPLE in FunGramKB's ontology.

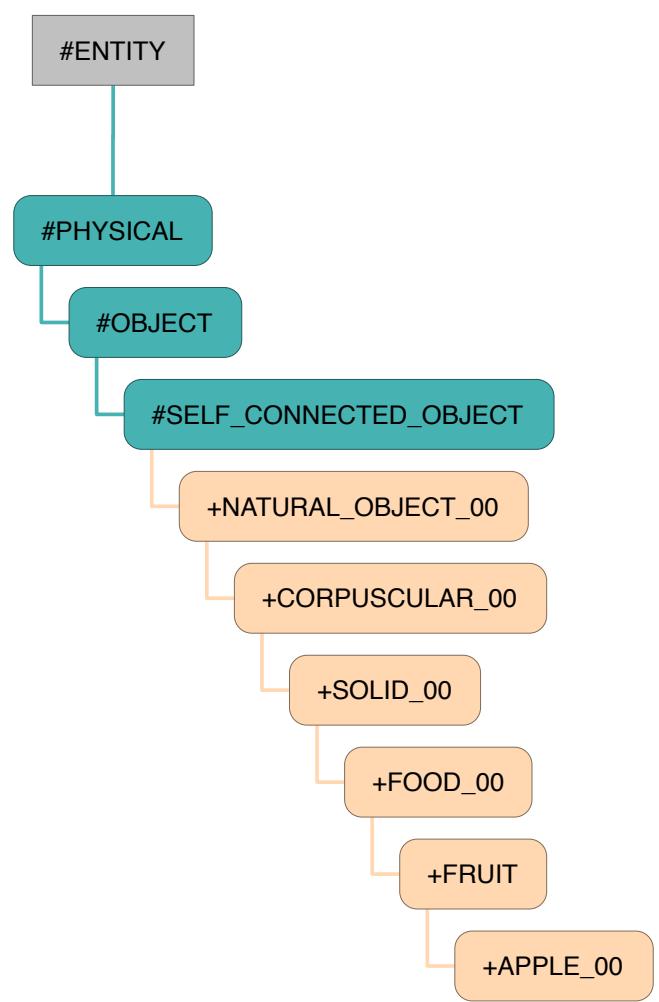

Figure 3. The conceptual string of the basic concept $+A P P L E_{-} 00$ in FunGramKB's ontology.

In Figure 3 we see that the concepts are hierarchically arranged. The one at the top level \#ENTITY is a root metaconcept which indicates that the category is an entity and not an event or a quality. Then we have three more metaconcepts hierarchically arranged: \#PHYSICAL, \#OBJECT and \#SELF_CONNECTED_OBJECT. The rewording of these three metaconcepts would be "a touchable entity, not made by a person, which is a whole in itself". In Figure 4 we find the interface of the metaconcepts in 
FunGramKB. They are not linked to any lexical unit. They are only defining concepts which help avoid circularity.

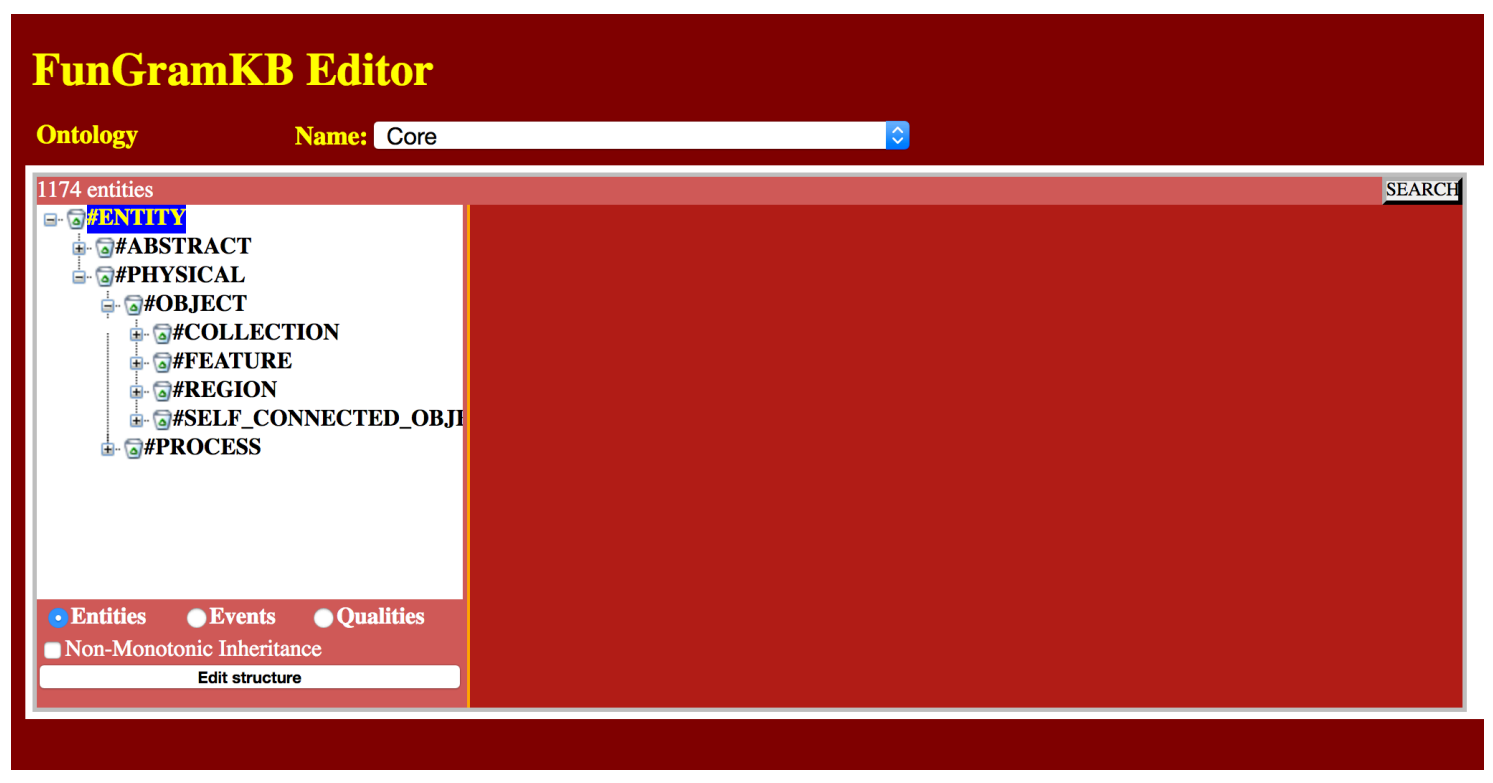

Figure 4. Metaconcepts in FunGramKB's ontology.

Finally, we find several basic concepts +NATURAL_OBJECT_00, +CORPUSCULAR_00, +SOLID_00, +FOOD_00, +FRUIT_00 and +APPLE_00. They can act as defining elements in meaning postulates and have words linked to them. They are also hierarchically arranged.

The description of each basic or terminal concept is represented by means of meaning postulates. A meaning postulate is made up of one or more connected predications, which carry the generic features of the concept. If a predication is preceded by the symbol " + " it means that it is always the case, and we call it "strict predication"; on the other hand, if it is preceded by the symbol "*", it means that, although that is a typical feature of the concept, it does not have to be always true, and it is called "refutable predication". As a way of illustration, in Figure 5 we present the predications, which appear in the meaning postulate of the concept +APPLE_00. 


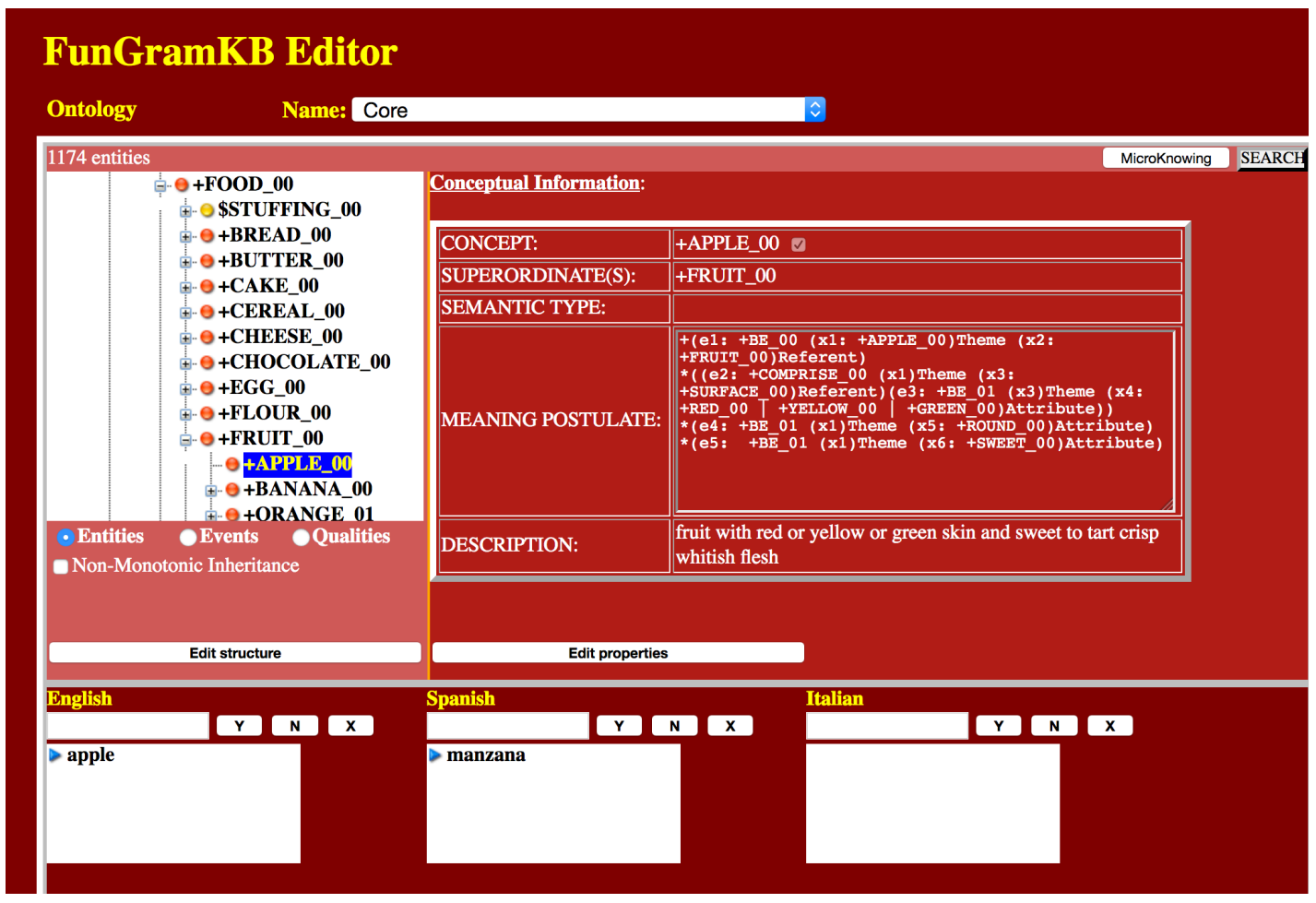

Figure 5. Basic concepts in FunGramKB's ontology: +APPLE_00.

Let's explain the meaning postulate of the basic concept +APPLE_00 in example 1:

(1)

a. +(e1: +BE_00 (x1: +APPLE_00)Theme (x2: +FRUIT_00)Referent)

b. *((e2: +COMPRISE_00 (x1)Theme (x3: +SURFACE_00)Referent)(e3: +BE_01 (x3)Theme (x4: +RED_00 | +YELLOW_00 | +GREEN_00)Attribute))

c. *(e4: +BE_01 (x1)Theme (x5: +ROUND_00)Attribute)

d. *(e5: +BE_01 (x1)Theme (x6: +SWEET_00)Attribute)

If we reword the previous representations we have:

a. An apple is always a fruit.

b. A typical apple has got a surface which can be red or yellow or green (although we can find pink apples).

c. A typical apple is round, but it cannot be the case (we could find apples which have an odd shape).

d. A typical apple is sweet (but there are also tart apples). 
It is relevant to mention here that the top-down organization of concepts is reflected in FunGramKB in a way that the same definition is inherited by all the entities belonging to a class. Thus, the information in the rubric DESCRIPTION for the concept +FRUIT_00 appears uniformly allocated to all the sister concepts existent in the conceptual hierarchy, such as +APPLE_00, +ORANGE_00 and +BANANA_00.

To finish this section, we would like to point out that due to the conceptualist approach that characterizes FunGramKB's ontology, the lexical units in the hierarchy are considered "atoms of grammar" (Periñán-Pascual \& Arcas Túnez, 2011, p. 4) which contain semantic knowledge in the form of meaning postulates.

In the case of nouns, the frame displaying the conceptual information is divided into five rubrics, each of which renders information with respect to (i) the LEXICAL UNIT; (ii) the CONCEPT; (iii) the SEMANTIC TYPE; (iv) the MEANING POSTULATE; and (v) a DESCRIPTION, as illustrated in Figure 6.

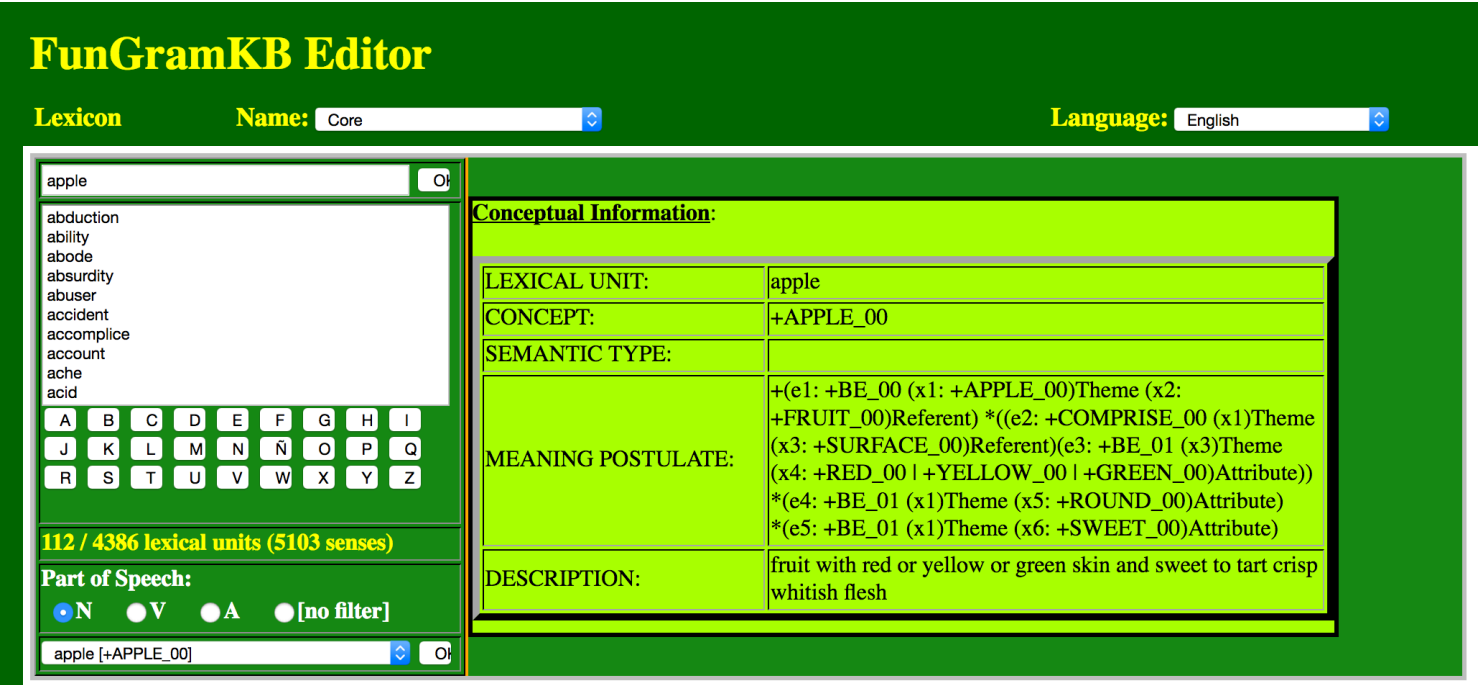

Figure 6. The lexicon in FunGramKB.

Once we have briefly introduced the architecture of FunGramKB, we are going to address the question of how FunGramKB can contribute to studies of semantic memory loss. Our proposal is to use FunGramKB ontology for three different tasks:

1. To check which features of a given category are damaged, and this will be accomplished by looking at which meaning postulates are absent in the production of features of a given concept.

2. To search for enriched conceptual networks established among concepts in FunGramKB by means of inheritance and inference mechanisms in order 
check if a lost feature in a given category would affect the same feature in semantically related categories.

3. To adopt the descriptors available in the ontology in order to refine the list of features used in the model designed by Peraita, Elosúa \& Linares (1992).

In what follows we are going to address the first two objectives and the third one will be dealt with in Section 5 .

As we have already stated, the terms categories and features used in the model by Peraita, Elosúa \& Linares (1992) correspond to concepts and meaning postulates respectively in FunGramKB. We are going to take three examples from the corpus elaborated by Peraita \& Grasso (2010) and analyse the production of features related to the category "apple" by three women, one healthy one, one with mild Alzheimer's disease and another one with moderate Alzheimer's disease ${ }^{5}$.

Case 1. Healthy Spanish woman aged 65, with primary education. The features compiled from her production test are the following:

Taxonomic: "it is a fruit".

Sensory evaluative: "it's green, red, yellow, of several colours, beautiful, tasty".

Functional: "it's edible, can be baked, can be stewed, for making compote, for making cakes".

Habitat: "there are very few here, they are brought from somewhere else".

Vital cycle: "they have just been harvested".

Others: "they are very much recommended (the baked ones), they are eaten both by grown ups and children".

Case 2. Spanish woman aged 67, with primary education. Diagnosed with Mild Alzheimer's disease. The features compiled from her production test are the following:

Functional: "for baking, for making pure".

Affective evaluative: "they are very nice".

Types: "some are red, others are yellow".

Case 3. Spanish woman aged 89, with primary education. Diagnosed with Moderate

5 We enclose the information from the corpus in the appendix. 
Alzheimer's disease. The features compiled from her production test are the following:

Functional: "they are mainly used natural, they are eaten stewed".

Sensory evaluative: "they are sort of green".

Affective evaluative: "it's the nicest, when baked they are very nice".

Types: "the reinette, the one with red skin".

At this point we have to go back to the hierarchical structure of the concept +APPLE_00 in Figure 3 to analyse which levels of the hierarchy are present in the production of our three participants in the corpus. We find out that case 1 is able to say that an apple is a fruit (+FRUIT_00) and that it is food ("it's for eating") (+FOOD_00). Case 2 does not mention the category "fruit" but somehow knows that it is food because of the function assigned "for baking, for making pure". Case 3 is similar to case 2 because she does not mention the category "fruit" but through the functional features assigned "they are mainly used natural, they are eaten stewed", we understand that she knows that an apple is food.

Thus, the first thing that calls our attention is that participants with Alzheimer's disease, be it mild or moderate, do not produce the word "fruit" while they are able to produce features lower in the hierarchy. It seems to be the case that semantic memory loss happens at the more general level of conceptualization.

Our second task was to look for enriched conceptual networks established among concepts in FunGramKB by means of inheritance and inference mechanisms in order check if a lost feature in a given category would affect the same feature in semantically related categories.

If we have a look at FunGramKB we find the following meaning postulates for the concepts +APPLE_00 and +FRUIT_00:

+APPLE_00

$+(\mathrm{e} 1:+\mathrm{BE}$-00 (x1: +APPLE_00)Theme (x2: +FRUIT_00)Referent)

*((e2: +COMPRISE_00 (x1)Theme (x3: +SURFACE_00)Referent)(e3: +BE_01 (x3)Theme

(x4: +RED_00 $\mid+$ YELLOW_00 $\mid+$ GREEN_00)Attribute) $)$

$*(\mathrm{e} 4:+\mathrm{BE}-01(\mathrm{x} 1)$ Theme $(\mathrm{x} \overline{5}:+\mathrm{ROUND} 00 \overline{0})$ Attribute $)$

*(e5: +BE_01 (x1)Theme (x6: +SWEET_00)Attribute)

+FRUIT_00

$+(\mathrm{e} 1:+$ BE_00 $(\mathrm{x} 1:+\mathrm{FRUIT}$ 00)Theme $(\mathrm{x} 2:+\mathrm{NATURAL}$ _OBJECT_00 \& + CORPUSCULAR_00 \& +SOSOLID_00 \& +FOOD_00 \& +PLANT_PART_00)Referent)

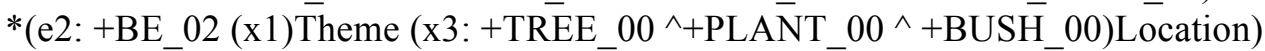

*(e3: +COMPRISE_00 (x1)Theme (x4: +SEED_00)Referent) 
*(e4: +BE_01 (x1)Theme (x5: +SWEET_00)Attribute)

We propose to establish enriched conceptual networks in order to detect inheritance and inference relations among concepts. The former would represent the onomasiological structure of concepts and the latter would depict the interrelation between concepts, more precisely, among their meaning postulates. For example, if we have the concept +APPLE_00 and its superordinate +FOOD_00, we can check not only whether the conceptual string is lost at a certain point, as it happened with our previous samples of patients with Alzheimer's disease, but we can also check if the features which are lost, and are shared by several concepts, are also lost in the production of attributes of those categories. In order to clarify the point, it would be interesting to know if the patients who could not retrieve the feature "is a fruit" in the production test about "apple", would be able to produce that attribute when asked about a different fruit, for instance, a banana. In that way we would be able to find out if features or categories which are lost in a certain production test, do affect other related categories where they are present too. Let's put it in a graphical way (Figure 7).

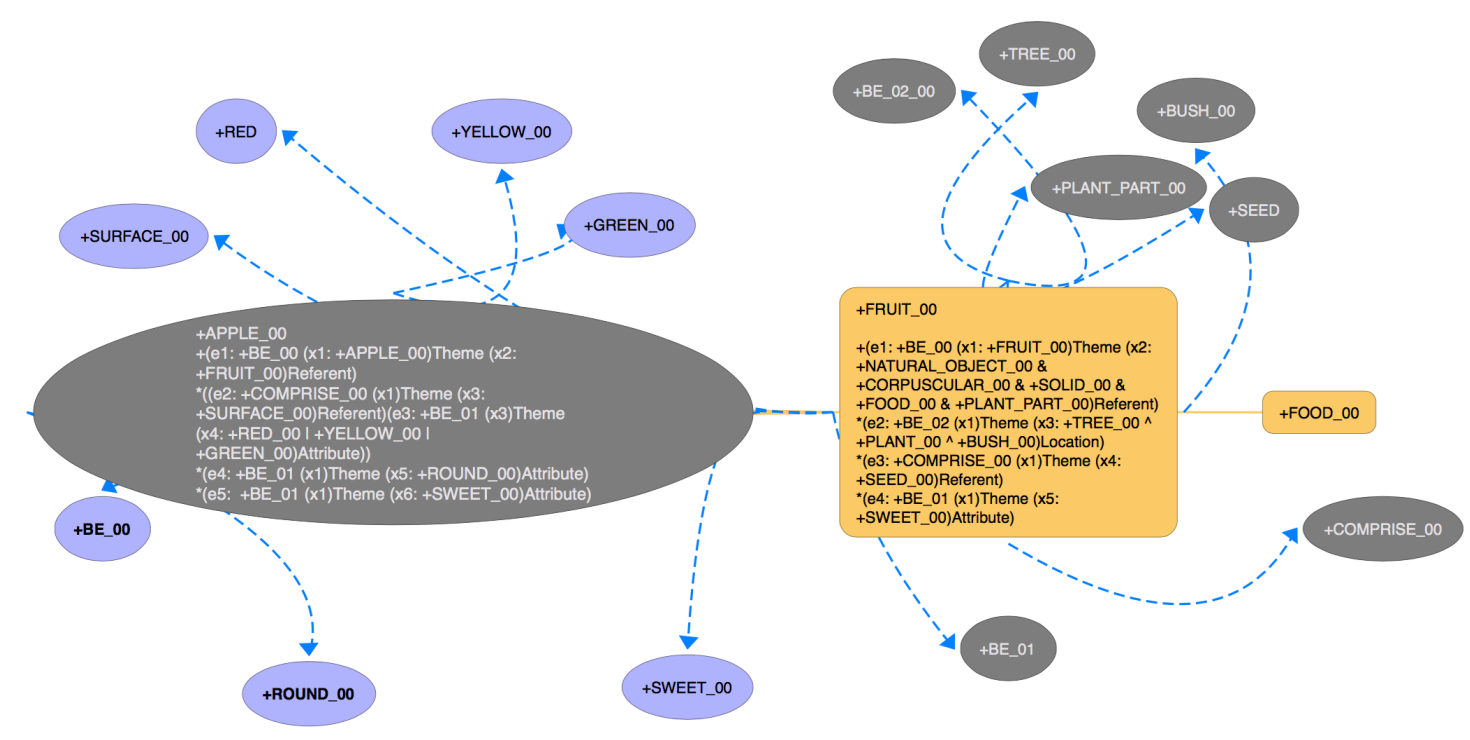

Figure 7. Inheritance and inference relations in FunGramKB.

In Figure 7 we have the representation of the hypernym concept +FRUIT_00 and its hyponym +APPLE_00. As we explained in the last section, concepts in FunGramKB's ontology are represented by means of meaning postulates which, in their turn, are made up of predications. The first predication contains the information of its immediate father concept in the ontology and in that way, its information is 
inherited. So in the case of +FRUIT_00, the information of its hypernym +FOOD_00 is inherited as reflected in its first strict predication +(e1: +BE_00 (x1: +FRUIT_00)Theme (X2: +NATURAL_OBJECT_00 \& +CORPUSCULAR_00 \& +SOLID_00 \& +FOOD_00 \& +PLANT_PART_00)Referent). The same happens with the concept +APPLE_00, which inherits the information from its immediate father in the hierarchy +FRUIT_00 which is reflected in the first strict predication +(e1: +BE_00 ( $x 1$ : +APPLE_00)Theme $(x 2$ : +FRUIT_00)Referent). As for the inference relations, we can see that every meaning postulate within a concept is defined through basic concepts. The microknowing in FunGramKB (Periñán-Pascual \& Arcas Túnez, 2005), which falls out of the topic of this paper, gives us the extended meaning postulate, and puts in connection the basic concepts which appear in the meaning postulates in the ontology.

As a way of conclusion of this section, we would like to say that we believe that by using meaning postulates we would enrich the relations between features and categories defined in the model by Peraita, Elosúa \& Linares (1992). But there is still a task ahead for this to be possible which we will expose in Section 5.

\section{Feature descriptors in FunGramKB's ontology}

In Jiménez Briones, Luzondo Oyón \& Pérez Cabello de Alba (2011) we find the protocol followed to elaborate the ontology in FunGramKB. That work focuses on the root metaconcept \#EVENT and here we are going to explain the way we have dealt with the root metaconcept \#ENTITY, making special emphasis on the descriptors we have used to define our basic and terminal concepts. Those descriptors will enrich the catalogue used in the model by Peraita, Elosúa \& Linares (1992).

When dealing with entities in FunGramKB, we have to define their semantic properties, which are contained in their meaning postulate (MP). A MP is a cognitive construct which represents the characteristics of a concept and, as we have already explained in Section 4, it is made up of one or more connected predications, which carry the generic features of the concept (see Figure 5). In order to actually make the meaning postulates of a given concept, FunGramKB offers a series of descriptors (see Table 1) which account for the features or characteristics which the concept could possibly have. This is an inventory based on Putstejovsky's qualia structure (Pustejovsky, 1991, 1995). 


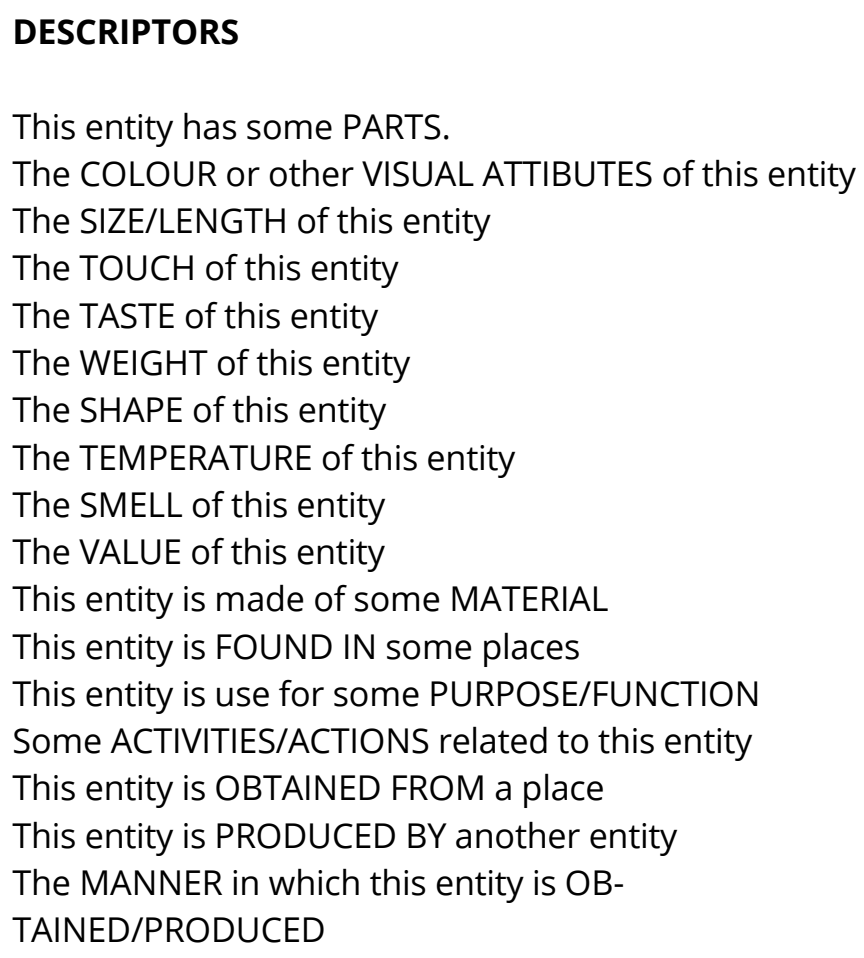

Table 1. Catalogue of descriptors used for the elaboration of meaning postulates in FunGramKB.

We will now move on to analyse the equivalences between the model designed by Peraita, Elosúa \& Linares (1992) and FunGramKB so that we can assess if our ontology will be useful for the treatment of the data retrieved in their studies.

If we go back to Section 2, Figure 2, we find that the common conceptual components for the categories Living Beings and Non Living Beings are, in the vertical axis, Taxonomy and Typification. In FunGramKB inheritance relations account for typification, and the first predication of every concept always contains the relation of the concept with its immediate father. Taxonomy, on the other hand, is also accounted for in terms of inheritance, and all concepts that hold a relationship of sisterhood will be under the same father concept, so they will then share the $x 2$ component of their first strict predication. Let's illustrate this point with the cases of the concepts +APPLE_00 and +BANANA_00 in (2).

(2)

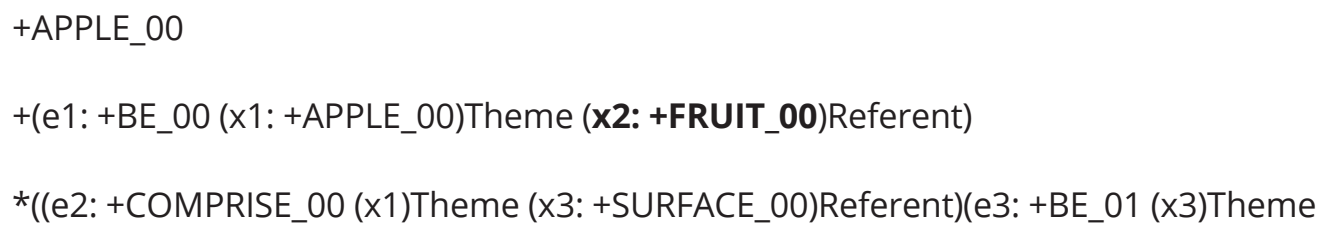


(x4: +RED_00 | +YELLOW_00 | +GREEN_00)Attribute))

*(e4: +BE_01 (x1)Theme (x5: +ROUND_00)Attribute)

*(e5: +BE_01 (x1)Theme (x6: +SWEET_00)Attribute)

+BANANA_00

+(e1: +BE_00 (x1: +BANANA_00)Theme (x2: +FRUIT_00)Referent)

*(e2: +BE_01 (x1)Theme (x3: +YELLOW_00)Attribute)

*(e3: +BE_01 (x1)Theme (x4: +LONG_00)Attribute)

+(e4: +BE_01 (x1)Theme (x5: +CURVED_00)Attribute)

Through inference relations, we can also see the features that concepts share with other entities of the ontology. So, for instance, if we find a given feature such as +SWEET_00 in the meaning postulate of APPLE_00, and we have the same feature in another concept such as +CAKE_00, as exemplified in (3), we can assume that if someone is asked to name sweet things, they will say both apple and cake.

(3)

+APPLE_00

+(e1: +BE_00 (x1: +APPLE_00)Theme (x2: +FRUIT_00)Referent)

*((e2: +COMPRISE_00 (x1)Theme (x3: +SURFACE_00)Referent)(e3: +BE_01 (x3)Theme (X4: +RED_00 | +YELLOW_00 | +GREEN_00)Attribute))

*(e4: +BE_01 (x1)Theme (x5: +ROUND_00)Attribute)

*(e5: +BE_01 (x1)Theme (x6: +SWEET_00)Attribute)

+ CAKE_O0

+(e1: +BE_00 (x1: +CAKE_00)Theme (x2: +ARTIFICIAL_OBJECT_00 \& + +CORPUSCULAR_00 \& +SOLID_00 \& +FOOD_00)Referent)

+(e2: +BE_01 (x1)Theme (x3: +SWEET_00)Attribute)

*((e3: +BAKE_00 (x4)Theme (x1)Referent)(e4: +COMPRISE_00 (x1)Theme (x4: +EGG_00 \& +FLOUR_00 \& +SUGAR_00)Referent)) 
Finally, the relations given in the horizontal axis of the model by Peraita, Elosúa \& Linares (1992) are accounted for by the descriptors of FunGramKB, which have been listed in Table 1, and which in fact constitute a richer catalogue of semantic features for the description of categories.

\section{Conclusions}

By using FunGramKB ${ }^{6}$ s ontology, we have met the objective of enhancing the protocol of features or conceptual components used in the test of semantic attributes production for the detection of semantic memory impairment employed in the studies by Peraita \& Grasso (2010) and Grasso, Díaz \& Peraita (2011).

On the other hand, since FunGramKB ontology is built upon inheritance relations, we can help in the identification tasks of memory loss. We could for instance detect the point of the conceptual string where a breakdown is produced.

Finally, through the semantic relation of inference, which is also present in FunGramKB ontology, we could also evaluate whether the loss of a given attribute would affect other concepts which contain the same attribute.

In the light of the results obtained in this study, we can conclude that by using an NLP system such as FunGramKB, we can help make studies on semantic memory loss more fine-grained so that they can be more accurate with regard to the diagnosis of Alzheimer's disease.

\section{About the author}

Dr Beatriz Pérez Cabello de Alba is Associate Professor of English Language and

$6 \quad$ We would like to mention some other initiatives related to knowledge and lexical representation which have also dealt with semantic memory (this is not a full list): Knowledge Master (KM) software tool for knowledge representation. It is oriented towards teaching. Rodríguez. (2010); The Nombela* 2.0 semantic battery: An updated Spanish instrument for the study of semantic processing. Moreno-Martínez \& Rodríguez-Rojo (2015); Natural Finder and Definition Finder, Vivas et al. (2014); and Bayesian Network Model to Support Diagnosis of Cognitive Impairment Compatible with an Early Diagnosis of Alzheimer's Disease. Guerrero, Martínez-Tomás, Rincón \& Peraita (2015). 
Linguistics at the UNED in Madrid (National University for Distance Learning), where she teaches Linguistics, English for Specific Purposes (ESP) and Translation (legal, scientific-technical and economic-commercial). She also teaches several courses in the UNED European Masters of English Applied Linguistics. Her research interests cover lexicology, lexicography, ontological semantics, natural language processing, neurolinguistics and clinical linguistics. She has collaborated in several competitive research projects and is currently working in a project funded by the Spanish Ministry of Economy and Competitiveness FFI2014-53788C3-1P working on FunGramKB's virtual laboratory (www.fungramkb.com). She has been a visiting scholar at the Universities of Amsterdam and Verona. She has also been visiting professor at Chulalongkorn University in Bangkok, and lecturer at the London School of Economics and Political Science, and Kingston University.

\section{Acknowledgements}

This work has been partially funded by research projects FFI2014-53788-C3-1$\mathrm{P}$ (Spanish Ministry of Economy and Competitiveness).

\section{Article history}

Paper received: 20 February 2017

Paper received in revised form and accepted for publication: 28 April 2017

\section{References}

Atkinson, R.C. \& Shiffrin, R.M. (1968). Human memory: A proposed system and its control processes. In K. W. Spence \& J. T. Spence (Eds.) The psychology of learning and motivation (Vol 2). (pp. 89-165). London: Academic Press.

Atkinson, R.C., \& Shiffrin, R.M. (1971). The control processes of short-term memory. Institute for Mathematical Studies in the Social Sciences. Stanford University.

Grasso, L., Díaz, M.C. \& Peraita, H. (2011). Deterioro de la memoria semántico-conceptual en pacientes con enfermedad de Alzheimer. Análisis cualitativo y cuantitativo de los rasgos semánticos producidos en una tarea verbal de definición categorial. Psicogeriatría 3(4), 159-165. 
Guerrero, J.M., Martínez-Tomás, R., Rincón, M. \& Peraita, H. (2015). Diagnosis of cognitive impairment compatible with an early diagnosis of Alzheimer's disease. A Bayesian network model based on the analysis of oral definitions of semantic categories. Methods Inf Med 1, 42-49.

Jiménez Briones, R., Luzondo Oyón, A. \& Pérez Cabello de Alba, M.B. (2011). FunGramKB y la organización ontológica. Anglogermánica Online 8, 16-36.

Mairal Usón, R. (2012). La arquitectura de una base de conocimiento léxico conceptual: implicaciones lingüísticas. In M. Giammatteo, L. Ferrari \& H. Albano (Eds.), Léxico y sintaxis.: Volumen temático de la serie editada por la Sociedad Argentina de Lingüística (183210). UNCuyo: Editorial FFyL.

Mairal Usón, R. \& Periñán-Pascual, C. (2009). The anatomy of the lexicon within the framework of an NLP knowledge base. Revista Española de Linguística Aplicada 22, 217244.

McLeod, S. A. (2007). Multi store model of memory - Atkinson \& Shiffrin, 1968. <http://www.simplypsychology.org/multi-store.html> [19/02/2017]

Miller, G. (1956). The magical number seven, plus or minus two: Some limits on our capacity for processing information. Psychological Review 101(2), 343-352.

Moreno-Martínez, F.J. \& Rodríguez-Rojo, I.C. (2015). The Nombela* 2.0 semantic battery: An updated Spanish instrument for the study of semantic processing. Neurocase, 21(6),77385.

Peraita, H., Díaz, C. \& Anllo-Vento, L. (2008). Processing of semantic relations in normal aging and Alzheimer's disease. Archives of Clinical Neuropsychology. 23(1), 33-46.

Peraita, H., Elosúa, R. \& Linares, P. (1992). Representación de categorías naturales en niños ciegos de nacimiento. Madrid:Trotta.

Peraita H., González-Labra M.J., Sánchez-Bernardos M.L. \& Galeote M.A. (2000). Batería de evaluación del deterioro de la memoria semántica en Alzheimer. Psicothema 12, 192-200.

Peraita, H. \& Grasso, L. (2010). Corpus lingüístico de definiciones de categorías semánticas de personas mayores sanas y con la enfermedad de Alzheimer. Una investigación transcultural hispano-argentina. Documento de trabajo BBVA. (Documentos de Trabajo 3, 2010) < http://www2.uned.es/investigacion-corpuslinguistico/> [19/02/2017].

Periñán-Pascual, C. \& Arcas Túnez, F. (2004). Meaning postulates in a lexico-conceptual knowledge base. 15th International Workshop on Databases and Expert Systems Applications, Los Alamitos (California). IEEE, 38-42.

Periñán-Pascual, C. \& Arcas Túnez, F. (2005). Microconceptual-knowledge spreading in FunGramKB. In Proceedings on the 9th IASTED International Conference on Artificial Intelligence and Soft Computing (pp. 239-244) Anaheim-Calgary-Zurich: ACTA Press.

Periñán-Pascual, C. \& Arcas Túnez, F. (2006). Reusing computer-oriented lexica as foreignlanguage electronic dictionaries. Anglogermánica Online 4, 69-93.

Periñán-Pascual, C. \& Arcas Túnez, F. (2007). Cognitive modules of an NLP knowledge base 
for language understanding. Procesamiento del Lenguaje Natural 39, 197-204.

Periñán-Pascual, C. \& Arcas Túnez, F. (2010). Ontological commitments in FunGramKB. Procesamiento del Lenguaje Natural 44, 27-34.

Periñán-Pascual, C. \& Arcas Túnez, F. (2011). Introducción a FunGramKB. Anglogermánica Online, 8, 1-15.

Pustejovsky, J. (1991). The generative lexicon. Computational Linguistics, 17(4), 47-81.

Pustejovsky, J. (1995). The generative lexicon. Cambridge, MA: MIT Press.

Raaijmakers, J.G.W. \& Shiffrin, R.M. (2003). Models versus descriptions: Real differences and language differences. Behavioral and Brain Sciences 26, 753.

Rodríguez, R.J. (2010). Herramientas informáticas para la representación del conocimiento. Software tools for knowledge representation. Subjetividad y Procesos Cognitivos 14(2), $217-$ 232.

Rodríguez-Rojo, I.C., Lugo-Marín, J. \& Moreno-Martínez, F.J. (2015). Category specificity, Alzheimer disease and normative studies: A review and several recent instruments for Spanish speakers. Austin Journal of Clinical Neurology 2(7), 1058.

Tulving, E. (1972). Episodic and semantic memory. In E. Tulving \& W. Donaldson (Eds.), Organization of memory (pp. 381-402). New York: Academic Press.

Vivas, J., et al. (2014). Organización reticular de la memoria semántica. Natural Finder y Definition Finder, dos métodos informatizados para recuperar conocimiento. Encontros Bibli: Revista letrônica de biblioteconomia e ciência da informação, 19(40), 235-252. 


\section{Appendix}

Sample of the corpus used in this work (Peraita \& Grasso, 2010)

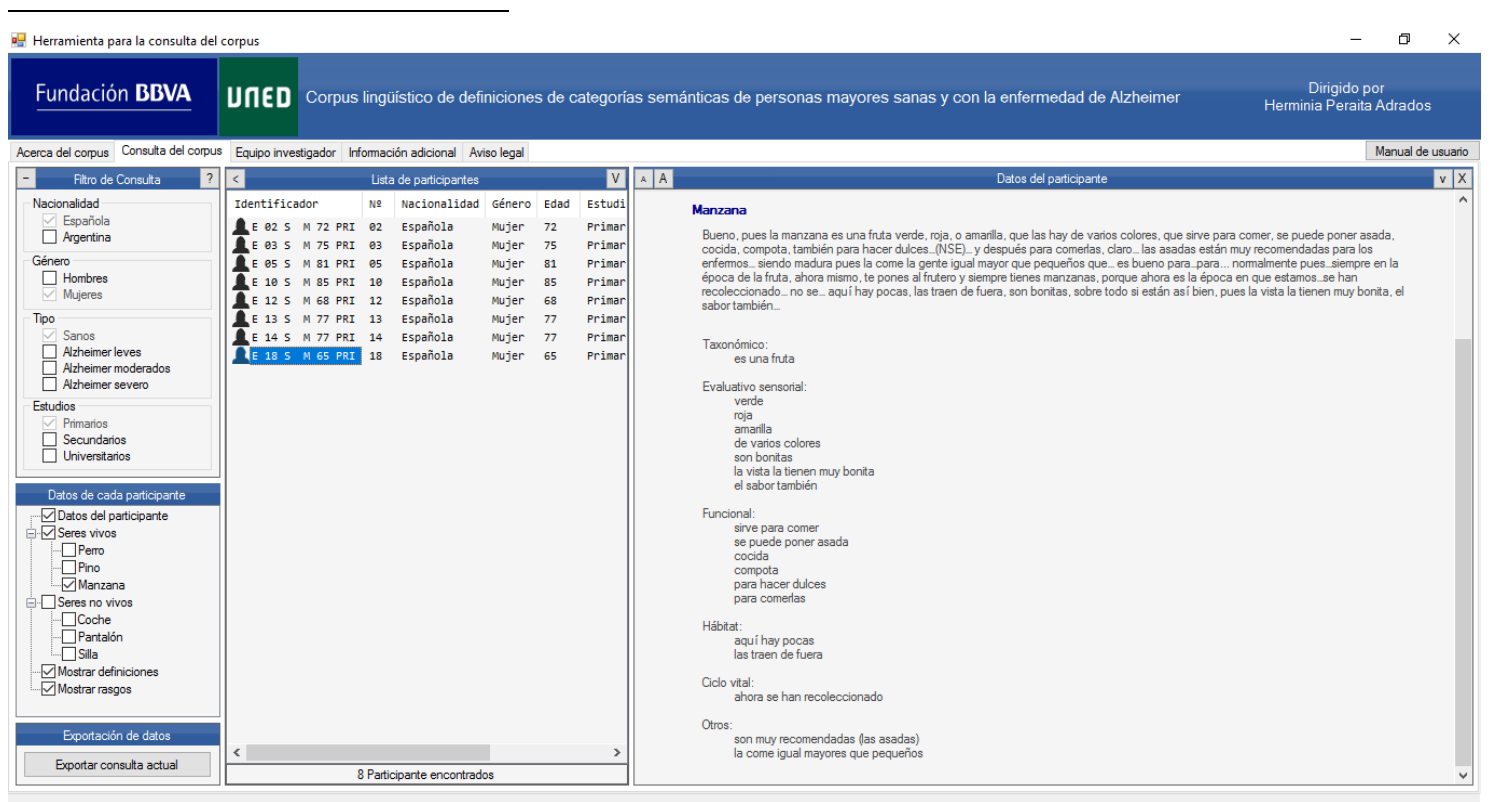

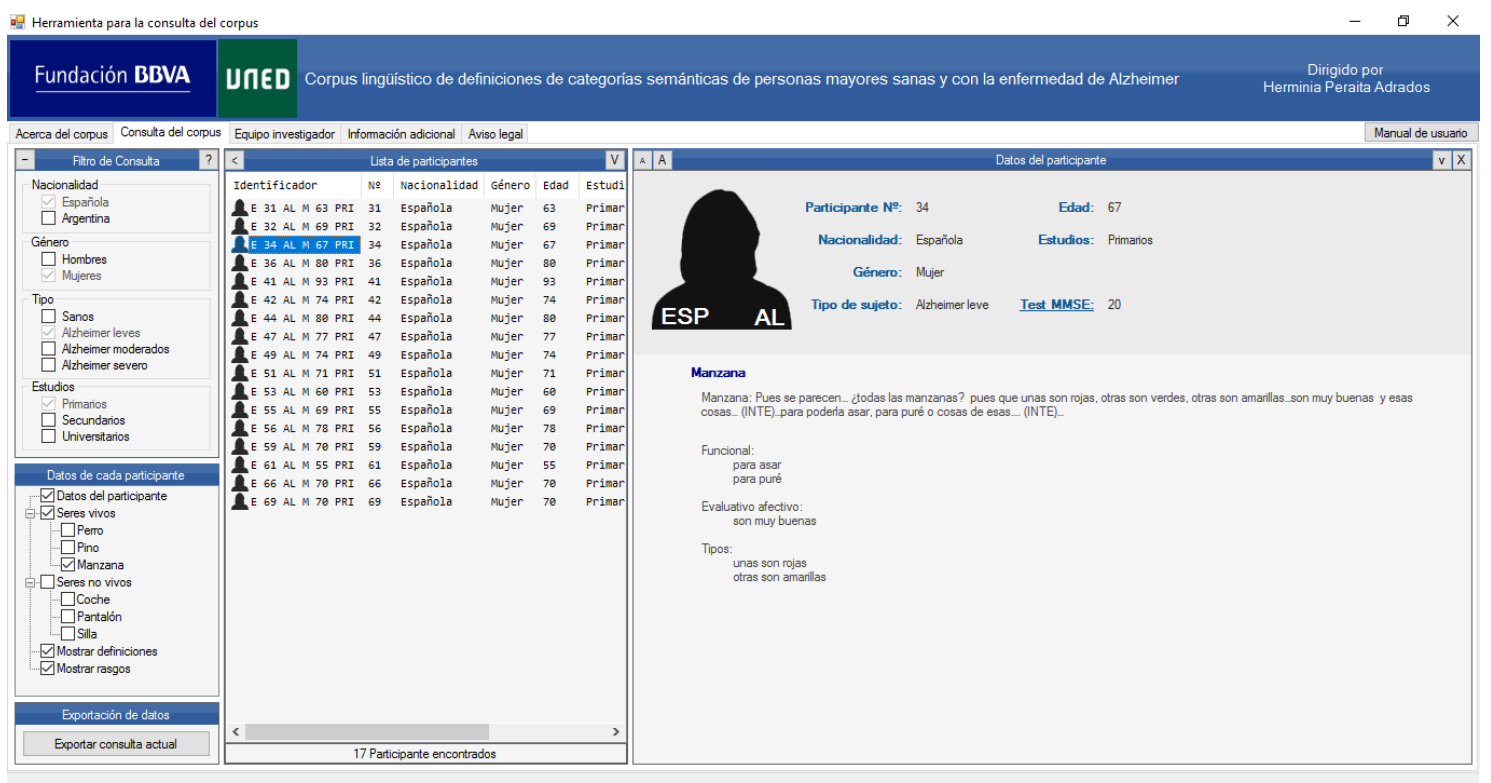




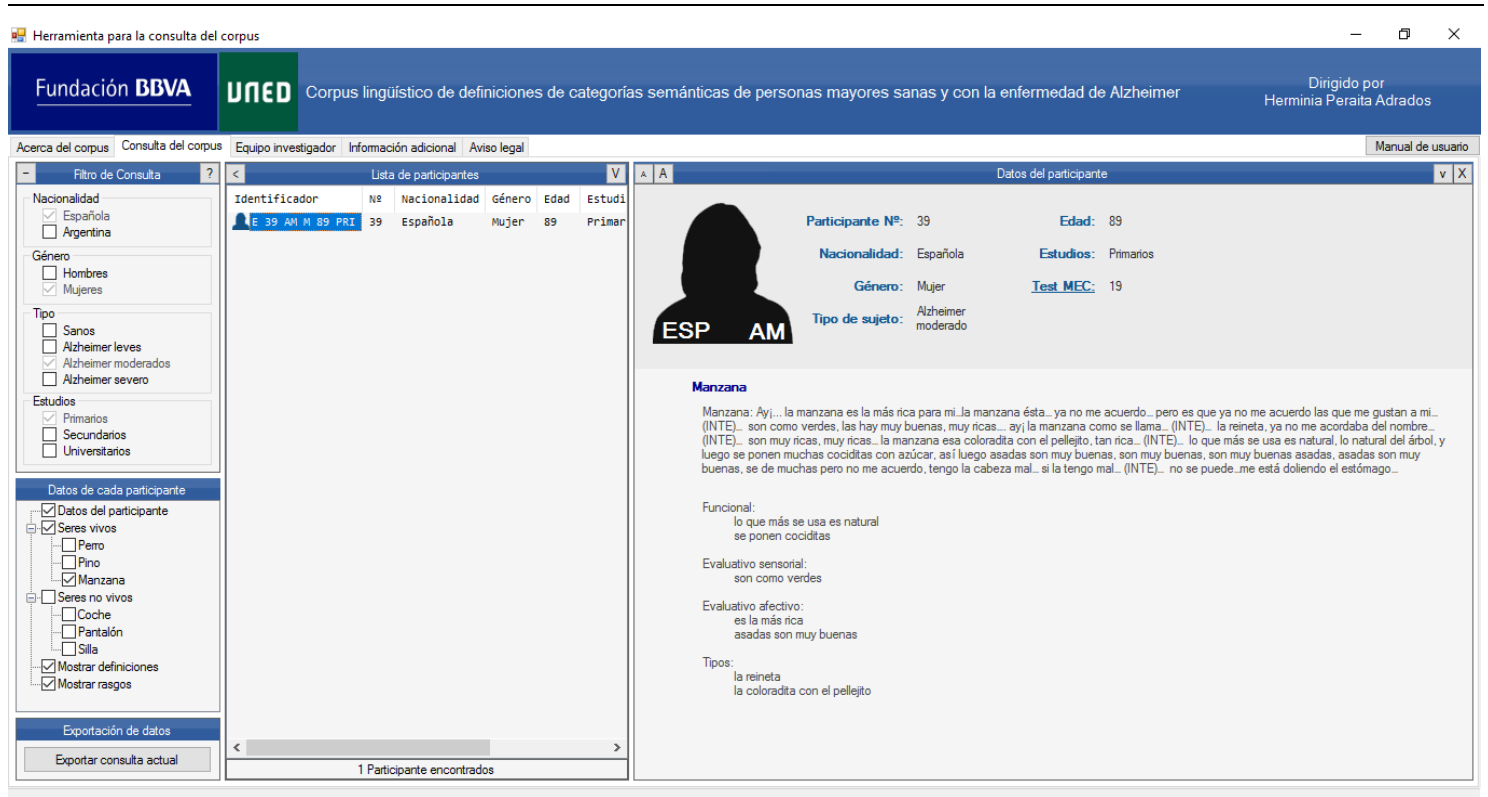

